\title{
AWARD OF THE NANSEN MEDAL TO A MEMBER OF THE RED CROSS
}

The person to whom Prince Sadruddin Aga Khan, United Nations High Commissioner for Refugees, presented the 1968 Nansen medal on October 10 last, in Geneva, was an active member of the Red Cross movement, Mr. Bernard Arcens. He is President of the Senegal Red Cross Casamance regional committee.

Since 1963, Mr. Arcens has been exerting every effort to organize local emergency relief to the refugees coming into the Casamance region. It was in recognition of Mr. Arcens' work that the Nansen Medal Committee decided unanimously to pay tribute to this dedicated member of the Red Cross.

During his visit to the League of Red Cross Societies Mr. Arcens mentioned that in 1965 the Senegal Red Cross had appealed to the League for assistance in launching, in close co-operation with the U.N. High Commissioner for Refugees, an emergency medical

programme for the benefit of the refugees arriving in Casamance. He paid warm tribute to the nurse who took part in that action through the offices of the League and several National Societies

\section{India}

In spite of the heavy burden imposed on it by two difficult years, the Indian Red Cross in 1967 was able not only to continue, but to extend its many humanitarian and charitable activities. This is made clear in the Annual Report submitted by Dr. S. Chandrasekhar, Chairman of the Society's Managing Body, to the 1968 Annual General Meeting at New Delhi in April under the chairmanship of Dr. Zakir Husain, President of India. ${ }^{1}$

${ }^{1}$ See Indian Red Cross Society, Proceedings of the Annual General Meeting, New Delhi, 1968. 